\title{
Accuracy of the pneumatic method for estimating xylem vulnerability to embolism in temperate diffuse-porous tree species
}

Sharath S. Paligi ${ }^{1,2, *}$, Roman M. Link ${ }^{1,7, *}$, Emilie Isasa ${ }^{1}$, Paulo Bittencourt ${ }^{3}$, Juliano Sarmento Cabral $^{4}$, Steven Jansen ${ }^{5}$, Rafael S. Oliveira ${ }^{6}$, Luciano Pereira ${ }^{5}$, Bernhard Schuldt ${ }^{1,7}$

1 University of Würzburg, Julius-von-Sachs-Institute of Biological Sciences, Chair of Ecophysiology and Vegetation Ecology, Julius-von-Sachs-Platz 3, 97082 Würzburg, Germany

2 Present address: Plant Ecology and Ecosystems Research, Albrecht von Haller Institute for Plant Sciences, University of Göttingen, Göttingen, Germany

3 College of Life and Environmental Sciences, University of Exeter, Exeter, United Kingdom

4 Ecosystem Modeling Group, Center for Computational and Theoretical Biology, University of Würzburg, Würzburg, Germany

5 Institute of Systematic Botany and Ecology, Albert-Einstein-Allee 11, Ulm University, D89081 Ulm, Germany

6 Department of Plant Biology, Instituto de Biologia, University of Campinas, Caixa Postal 6109, CEP 13083-970, Campinas, SP, Brazil

7 Corresponding authors: roman.link@plant-ecology.de

$$
\text { bernhard.schuldt@plant-ecology.de }
$$

* First and second author contributed equally to this work

Running title: Accuracy of the pneumatic method

\begin{tabular}{|c|c|c|}
\hline \multirow[t]{10}{*}{ Word count: } & Summary & 200 \\
\hline & Main body & 6,316 \\
\hline & Introduction & 1,040 \\
\hline & Materials and methods & 2,232 \\
\hline & Results & 695 \\
\hline & Discussion & 2,363 \\
\hline & Acknowledgements & 68 \\
\hline & Tables & 2 \\
\hline & Figures & 5 \\
\hline & Supporting information & 6 \\
\hline
\end{tabular}

Keywords: Cavitron, drought tolerance traits, xylem embolism resistance, vulnerability curve, methods comparison, Pneumatron, plant hydraulics. 


\section{Summary}

2 - The increasing frequency of global change-type droughts has created a need for fast, accurate

3 and widely applicable techniques for estimating xylem embolism resistance to improve

4 forecasts of future forest changes.

- We used data from 12 diffuse-porous temperate tree species covering a wide range of xylem safety to compare the pneumatic and flow-centrifuge method for constructing xylem vulnerability curves. We evaluated the agreement between parameters estimated with both methods and the sensitivity of pneumatic measurements to the measurement duration.

- The agreement between xylem water potentials at 50\% air discharged (PAD) estimated with the Pneumatron and 50\% loss of hydraulic conductivity (PLC) estimated with the flowcentrifuge method was high (mean signed deviation: 0.12 MPa, Pearson correlation: 0.96 after $15 \mathrm{sec}$ of gas extraction). However, the relation between the estimated slopes was more variable, resulting in lower agreement in xylem water potential at $12 \%$ and $88 \%$ PAD/PLC.

14 All parameters were sensitive to the duration of the pneumatic measurement, with highest overall agreement between methods after $16 \mathrm{sec}$.

- We conclude that, if applied correctly, the pneumatic method enables fast and inexpensive estimations of embolism resistance for a wide range of temperate, diffuse-porous species, which makes it attractive for predicting plant performance under climate change. 


\section{Introduction}

In the last decades, unprecedented climate fluctuations and the resulting extreme drought events have led to large-scale tree dieback events worldwide (Allen et al., 2010, 2015; Brando et al., 2019). With the global rise in frequency, intensity and duration of drought spells predicted by current climate projections (cf. Field et al., 2012; Trenberth et al., 2014), large-scale droughtinduced tree mortality events become increasingly likely (Brodribb et al., 2020).

To improve the prediction of demographic and compositional changes in forest ecosystems, a better understanding of physiological mechanisms associated with the death of trees in response to drought is necessary (Allen et al., 2010; McDowell et al., 2013a, 2013b). In this context, traits that quantify the vulnerability of a tree's xylem to drought-induced embolism have received particular attention (Choat et al., 2018; Brodribb et al., 2020). Vulnerability to embolism is usually expressed by the parameters of xylem vulnerability curves (VCs), i.e. curves describing the consecutive loss of hydraulic conductance (percent loss of conductivity, PLC) as a function of increasingly negative xylem pressures (cf. Sperry et al., 1988; Cochard et al., 2013). Most commonly, VCs are described by the water potential at 12,50 or $88 \%$ loss of hydraulic conductance $\left(P_{12}, P_{50}\right.$ and $P_{88}$, respectively) and the slope of the curve at one of the respective locations. The parameters of VCs have been linked to mechanistic thresholds for xylem functioning (cf. Brodribb \& Cochard, 2009; Urli et al., 2013; Delzon \& Cochard, 2014), and are closely coordinated with stomatal regulation (Martin-StPaul et al., 2017). Across biomes, xylem embolism resistance has been associated with the susceptibility of a species to drought-induced mortality (Anderegg et al., 2016; Adams et al., 2017; Correia et al., 2019; Powers et al., 2020) and thus mirrors the distribution of species along aridity gradients (Blackman et al., 2014; Trueba et al., 2017; Oliveira et al., 2019). Due to their immediate mechanistic interpretation, VC parameters and derived quantities such as hydraulic safety margins (Meinzer et al., 2009) are increasingly incorporated in process-based vegetation models to describe plant drought responses and associated drought-induced tree mortality 
(McDowell et al., 2013a, 2013b; Christoffersen et al., 2016; Xu et al., 2016; Davi \& Cailleret 2017; Eller et al., 2020).

Xylem VCs can be established through a large number of different techniques, such as the bench dehydration (Sperry et al., 1988), air injection (Cochard et al., 1992), flow-centrifuge (Cochard et al., 2005), micro-CT (Brodersen et al., 2010), pneumatic (Pereira et al., 2016), optical (Brodribb et al., 2016) and relative water loss method (Rosner et al., 2019). However, none of these methods is unequivocally reliable for angiosperm and gymnosperm species, either due to measurement artefacts associated with vessel length and porosity (Cochard et al., 2013; Jansen et al., 2015) or because they are not suitable for rapid measurements of large number of samples (Cochard et al., 2013; Nolf et al., 2017). Given their usefulness to predictive models, methods for the measurement of xylem embolism that are simple, accessible, reliable and applicable for a wide range of taxonomic groups and xylem types are needed.

A novel, promising route for fast indirect $\mathrm{VC}$ measurements is the pneumatic method (Pereira et al., 2016; Jansen et al., 2020), which estimates the amount of xylem embolism by measuring the increase of air volume in the xylem in bench-dried plant samples with increasingly negative xylem pressure. Recently, Pereira et al. (2020) proposed an automated device, the Pneumatron, which automatically measures air discharge from a plant sample at a high temporal resolution and permits a high sample throughput. As the measurement principle of the Pneumatron does not directly depend on the measurement of xylem water transport, and embolism is induced by bench dehydration, it is assumed to be relatively robust against measurement artefacts related to sample excision and preparation as well as vessel length related artefacts (Pereira et al., 2016, 2020), which are known to affect several hydraulic VC methods (cf. Choat et al., 2010; Wheeler et al., 2013; Martin-StPaul et al., 2014; Torres-Ruiz et al., 2014, 2015).

The pneumatic method has already been applied to construct VCs for branches, leaves and roots of tropical, subtropical and temperate species, covering diffuse-porous, ring-porous and coniferous species (Pereira et al., 2016, 2020; Zhang et al., 2018; Wu et al., 2020; Sergent et 
al., 2020). The results from these studies indicate the suitability of the method for diffuseporous (Pereira et al., 2016; Zhang et al., 2018; Sergent et al., 2020) and for ring-porous species (though the latter only after gluing growth rings other than the current year rings; cf. Zhang et al., 2018). However, Zhang et al. (2018) reported that the pneumatic method resulted in lower estimates of embolism resistance of two conifer species compared to the flow-centrifuge method. Similarly, in a recent methodological comparison of VC techniques, Sergent et al. (2020) found the pneumatic method to result in lower embolism resistance estimates compared to other methods in further two conifer species, and reported inconsistent estimates for longvesseled species. Several sources of uncertainty have been identified for the pneumatic method that leave room for potential methodological improvements. Notably, its estimates are known to be sensitive to the choice of the reservoir volume and the duration of the air discharge measurement (Pereira et al., 2016, 2020). Prior studies have used vastly different time intervals to measure air discharge (AD) from the xylem segment, ranging from $150 \mathrm{sec}$ (Pereira et al., 2016; Chen et al., 2021), over $120 \mathrm{sec}$ (Zhang et al., 2018; Sergent et al., 2020; Wu et al., 2020), to only $30 \mathrm{sec}$ (Pereira et al., 2020). Since a $15 \mathrm{sec}$ duration was predicted as optimal discharge time based on the Unit Pipe Pneumatic model (Yang et al., 2021), there is a need to test this hypothesis experimentally. Moreover, despite considerable attention to measuring artefacts and methodological concerns, we currently lack a rigorous statistical framework to compare embolism resistance methods.

This study uses a dataset of vulnerability curve measurements from 36 trees belonging to 12 temperate, diffuse-porous tree species to i) assess how well the parameters of the vulnerability curves obtained with the pneumatic method (Pneumatron) agree with estimates obtained from the flow-centrifuge method (Cavitron) in terms of systematic deviations, random deviations and overall agreement, and to ii) identify the optimal duration for air discharge measurements. 


\section{Materials and Methods}

\section{Plant material}

Plant material from trees belonging to 12 temperate diffuse-porous tree species (Table 1) was collected between mid-July and mid-September 2019 from a nursery in Veitshöchheim $\left(49^{\circ} 50^{\prime} 24.3^{\prime \prime} \mathrm{N}, 9^{\circ} 52^{\prime} 38.4^{\prime \prime E}\right)$ near Würzburg, Germany. These trees were planted in the year 2011 in the framework of a long-term comparative experiment designed to identify appropriate tree species for urban planting. The plant material cultivated in Veitshöchheim was obtained from selected nurseries across Central Europe. Due to anomalies in the data for some of the species (see below), additional branch samples were obtained from adult Tilia cordata and Tilia platyphyllos trees growing at Ulm University, Germany $\left(48^{\circ} 25^{\prime} 20.3^{\prime \prime} \mathrm{N}, 9^{\circ} 57^{\prime} 20.2^{\prime \prime} \mathrm{E}\right)$ and of Tilia japonica from the Würzburg botanical garden (4945'56.7"N 955'58.1"E) in September 2020.

The samples were collected before 9:30 a.m. to assure sample excision took place in a relaxed state, thus avoiding measurement artefacts associated with cutting under tension (Wheeler et $a l ., 2013)$. From each of the experimental trees, one sun-exposed branch $70-120 \mathrm{~cm}$ in length or any kind of damage to avoid leaks and consequent embolism overestimation. All suspicious leakage points were sealed using a fast-drying contact adhesive (Loctite 431 with Loctite activator SF 7452, Henkel, Düsseldorf, Germany). Fruits present on the branches were removed and sealed with the same glue, as they easily detach with progressing dehydration and are hence a potential site of air-entry. Similarly, in the case of Crataegus persimilis, thorns were removed and sealed in the same manner to ease the handling of the branches.

\section{Measurements of vulnerability curves with the pneumatic method}

Branch xylem vulnerability curves based on the pneumatic method (Pereira et al., 2016) were obtained for 44 samples from 35 experimental trees (Table 1) using the Pneumatron, a device 
that combines a microcontroller-activated vacuum pump and a pressure transducer to allow for automated measurements of air discharge (Pereira et al., 2020; Jansen et al., 2020). The reservoir pressure was tracked with the Pneumatron in $0.5 \mathrm{sec}$ intervals over a span of two minutes per measurement (including a pump time of approximately $2 \mathrm{sec}$ in semi-automated mode and few milliseconds in automated mode). The amount of air discharged (AD) into the 126 reservoir was calculated based on the ideal gas law (Pereira et al., 2016). The semi-automated mode of the Pneumatron was used to measure AD for the samples obtained from Veitshöchheim and Würzburg, whereas the additional branch samples of T. cordata and T. platyphyllos processed in Ulm were measured in automated mode. After each AD measurement, the xylem water potential was measured (see below). The maximum detectable amount of AD is 131 associated with a change of pressure in the system by $\sim 50 \mathrm{kPa}$ (Pereira et al., 2020). As the

132 time necessary for a pressure change of $50 \mathrm{kPa}$ depends on the ratio between the reservoir 133 volume (including the cut-open conduit volume) and the volume of gas extracted from intact, 134 embolised conduits, the choice of the optimal reservoir volume is crucial (cf. Pereira et al., 135 2020). For this study, reservoir volumes of $1.7-3.3 \mathrm{ml}$ were selected based on the available 136 information about the species' embolism resistance from the xylem functional traits database

137 (Choat et al., 2012), assuming that higher embolism resistance corresponds to a lower volume 138 of gas extracted from intact, embolised conduits and hence a lower optimal reservoir volume 139 and vice-versa. Meanwhile, however, Pereira et al. (2020), recommend determining the 140 maximum reservoir volume from a completely dried branch per species. Throughout the 141 measurements, the volume of the vacuum reservoir was kept constant for each branch.

142 Once the branch was fully hydrated, a clean cut was made in air at the basipetal end using a 143 sharp razor blade to clear obstructions for air flow (Pereira et al., 2016; Jansen et al., 2020).

144 Although this seems counterintuitive at first glance, cutting in air was done intentionally 145 because the cut-open conduits need to be embolised when starting pneumatic measurements. 146 The branch was then connected to the pneumatic apparatus using rigid and elastic tubing, plastic 
147 clamps and three-way stopcocks (Fig. S1, S2). The volume of the elastic tube was kept as small

148 as possible to minimize pressure-dependent changes in reservoir volume. The elastic tubing

149 was tightened with a plastic clamp to ensure no leakage occurred during the measurement

150 (Bittencourt et al., 2018). Before each series of measurements and in case of suspicious

151 increases in the amount of $\mathrm{AD}$, the connections and the plant material were thoroughly

152 inspected to identify and seal potential air-entry points.

153 Before AD measurements were taken, the branch samples were bagged in dark plastic bags to

154 equilibrate water potential. During $\mathrm{AD}$ measurement, the branches were kept bagged to

155 minimize transpiration. Between measurements, the branches were dehydrated at room

156 temperature on a laboratory bench to induce embolism (Sperry et al., 1988). The branches were

157 initially dried for intervals of about $15-30 \mathrm{~min}$, which were subsequently increased to $1-4 \mathrm{~h}$

158 depending on how quickly the sample dried. To allow xylem water potential to equilibrate after

159 each drying interval, the samples were bagged for about $30 \mathrm{~min}$ in the initial steps of

160 dehydration, and for at least one hour in the later stages to account for the decrease in the leaf-

161 stem conductance (cf. Pereira et al., 2016). AD measurements were made on multiple branches

162 on the same day (see Fig. S1 - S3). The elastic tubing was always kept connected to the branch

163 samples when switching branches to keep the reservoir volume constant throughout all

164 measurements. AD measurements were taken until the branches were completely dehydrated

165 and no considerable variation was observed in the amount of $\mathrm{AD}$ in consecutive measurements

166 over at least $24 \mathrm{~h}$, or until the maximum absolute xylem water potential measurable with the

167 Scholander pressure chamber (10 MPa) was reached. This resulted in measurement durations

168 of $3-7$ days as well as in $10-20 \mathrm{AD}$ and leaf water potential measurements per branch when

169 following the semi-automated mode of the Pneumatron. The percentage of air discharged

170 (PAD) was calculated as described by Pereira et al. (2016):

$171 P A D_{i}=100 *\left(A D_{i}-A D_{\min }\right) /\left(A D_{\max }-A D_{\min }\right)$, 
where $A D_{i}$ is the amount of air discharged for measurement $i, A D_{\min }$ is the minimum amount of air discharged from the fully hydrated branch, and $A D_{\max }$ is the maximum amount of air discharged from the branch when completely desiccated.

Xylem water potential measurement

177 For the 35 branch samples measured in semi-automated mode, the xylem pressure was measured with a Scholander pressure chamber (PMS Instruments, Corvallis, Oregon, USA) after every AD measurement. At each pressure step, two leaves were cut-off from the branch, and xylem water potential was averaged over two pressure chamber measurements. When the

181 petiole was too small for measurement in the pressure chamber, small terminal twigs were used.

182 The cut was immediately sealed using an instant adhesive (Loctite 431) to prevent leakage 183 during the subsequent $\mathrm{AD}$ measurements. For the nine branches of $T$. cordata and $T$. platyphyllos measured using the automated mode of a Pneumatron, a stem psychrometer (ICT International, Armidale NSW Australia) was installed at a distal part of the branch to record xylem pressures for every $15 \mathrm{~min}$. To obtain pressure estimates for each point in time and to reduce the impact of measurement uncertainty in the psychrometric water potentials, the psychrometer measurements for each sample were smoothed with shape-constrained additive models using monotone decreasing P-splines based on R package scam v. 1.2-8 (Pya, 2020).

Measurements of vulnerability curves with the flow-centrifuge method

192 The flow-centrifuge technique (Cavitron; Cochard et al., 2005) was used as a reference method

193 for comparing the agreement of xylem vulnerability curves based on hydraulic measurement

194 methods with curves based on the Pneumatron. Flow-centrifuge measurements were performed 195 for 49 samples from 36 trees with a Cavitron device built from a Sorval RC 5 series centrifuge 196 with manual control of rotation speed, and using the Cavisoft software (Cavisoft version 
water to a final length of $27.5 \mathrm{~cm}$ to release the tension in the xylem (Torres-Ruiz et al., 2015).

199 Subsequently, the non-flushed branch segments were inserted in a custom-made rotor after removing the bark at both ends. They were then spun using the principle of centrifugal force to generate a negative pressure in the xylem segment while simultaneously measuring hydraulic conductance. Flow centrifuge measurements were performed with filtered $(0.2 \mu \mathrm{m})$ and degassed demineralized water that was enriched with $10 \mathrm{mM} \mathrm{KCl}$ and $1 \mathrm{mM} \mathrm{CaCl}$. Measurements began at xylem water potentials of around -0.8 MPa and were continued under increasingly negative xylem pressures until the percentage loss of hydraulic conductivity (PLC) reached at least $90 \%$.

Statistical analysis

All data handling and statistical analyses were performed in $\mathrm{R}$ version 4.0.2 ( $\mathrm{R}$ Core Team, 2020) in the framework of the tidyverse (Wickham et al., 2019). Both the vulnerability curves based on pneumatic and flow-centrifuge measurements were described with tree-level

212 nonlinear regression models using the logistic function by Pammenter \& Van der Willigen 213 (1998). For the flow-centrifuge method, vulnerability curves were based on the raw 214 conductivity measured by the Cavitron (cf. Ogle et al., 2009):

$K_{i}=$ Normal $\left(k_{\text {sat }}\left(1-\frac{1}{1+\exp \left(\frac{S_{50 H}}{25}\left(\mathrm{P}_{\mathrm{i}}-\mathrm{P}_{50 H}\right)\right)}\right), \sigma\right)$,

216 where $K_{i}$ and $P_{\mathrm{i}}$ are the measured hydraulic conductivity and xylem pressure for observation $i$, 217 respectively, $k_{\text {sat }}$ is the hydraulic conductivity under fully saturated conditions, and $S_{50 \mathrm{H}}$ is the 218 slope at $50 \%$ loss of conductivity $\left(P_{50 \mathrm{H}}\right)$. For the pneumatic measurements, analogous models 219 were constructed based on PAD for estimating $P_{50 \mathrm{P}}($ Eq. 1):

$P A D_{i}=$ Normal $\left.\left(\frac{100}{1+\exp \left(\frac{S_{50 P}}{25}\left(\mathrm{P}_{\mathrm{i}}-\mathrm{P}_{50 P}\right)\right.}\right), \sigma\right)$, 
To evaluate the effect of the air-discharge time on the accuracy of the estimates of vulnerability curve parameters, separate pneumatic vulnerability curves were fit on PAD calculated for all measurement durations between the initial pressure immediately after pumping and variable and $88 \%$ loss of conductivity, respectively) were calculated from the estimated model parameters ( $P_{50}$ and the corresponding slope at this pressure) by rearranging the model equation (Eqs. $2 \& 3)$, and with confidence intervals based on parametric bootstrap $(n=10,000)$. The uncertainty in $\mathrm{VC}$ parameters was taken into account for the calculation of species averages of

VC parameters and their standard errors by using inverse-variance weighting analogous to a

230 fixed-effects meta-analytical model (cf. Rosenberg et al., 2013).

231 We subsequently calculated a set of statistics that describe the degree of agreement of the

232 Pneumatron parameter estimates with the flow-centrifuge based values in terms of systematic

233 deviations, random deviations, and overall agreement. For the Pneumatron measurements from

234 Tilia japonica, T. cordata and T. platyphyllos, these calculations were based on tree averages 235 of the flow-centrifuge parameters when replicate measurements were performed per tree (Tab. $2361)$

237 Systematic deviations between Pneumatron and flow-centrifuge based VC parameter estimates 238 were quantified by the mean signed deviation (MSD). The MSD only measures additive bias 239 between the parameter estimates obtained by the pneumatic and flow-centrifuge methods $\left(\theta_{\mathrm{P}}\right.$ 240 and $\theta_{\mathrm{H}}$, respectively) and does not penalize scatter in the relationship.

$241 \quad \mathrm{MSD}=\frac{1}{n} \sum\left(\theta_{P}-\theta_{H}\right)$

242 Random deviations between the estimates of both methods was evaluated by the Pearson 243 correlation $\rho$ between $\theta_{\mathrm{P}}$ and $\theta_{\mathrm{H}}$. The correlation coefficient only penalizes the degree of scatter 244 around a hypothetical line through $\theta_{\mathrm{P}}$ and $\theta_{\mathrm{H}}$ and does not include information about systematic 245 differences. 
247 The overall agreement of the parameter estimates was evaluated by the root mean square 248 deviation (RMSD). Unlike the aforementioned metrics, the RMSD penalizes both systematic 249 and random deviations between $\theta_{\mathrm{P}}$ and $\theta_{\mathrm{H}}$.

$\operatorname{RMSD}=\sqrt{\frac{1}{n} \sum\left(\theta_{P}-\theta_{H}\right)^{2}}$

251 In addition, as a pragmatic measure to quantify the overall match of the flow-centrifuge and 252 pneumatic vulnerability curves over their entire range, we calculated the $\mathrm{L}_{2}$ distance (cf. 253 Cramér, 1928) between each pair of flow-centrifuge and pneumatic vulnerability curves:

$L_{2}=\left(\int_{-\infty}^{\infty}\left(P L C_{H}(P)-P L C_{P}(P)\right)^{2} \mathrm{dP}\right)^{1 / 2}$

255 This quantity describes the degree of similarity of the two vulnerability curves and approaches 256 zero for identical curves.

257 In addition to the comparison of metrics describing the agreement between estimates, we used 258 linear mixed effects models based on R package lme 4 version 1.1-23 (Bates et al., 2015) to test for statistically significant differences between the Cavitron-based estimates of $P_{12}, P_{50}, P_{88}$ and (natural log-transformed) $\mathrm{S}_{50}$ and their Pneumatron-based equivalents for AD intervals of $15,30,60,90$ and $115 \mathrm{sec}$ from the initial pressure at $4 \mathrm{sec}$. Each model was fit to each 262 parameter using restricted maximum likelihood with "method" as a fixed effect and random 263 intercepts for species and individual trees nested in species. The flow-centrifuge was considered 264 as baseline and contrasted with each one term for the Pneumatron estimates in five different 265 intervals. Model assumptions were checked by residual diagnostic plots. Inference was based 266 on Wald $t$-tests with Sattherthwaite's approximation to the degrees of freedom using R package 267 lmerTest version 3.1-2 (Kuznetsova et al., 2017). 


\section{Results}

\section{0 \\ Estimated vulnerability curves}

271 The average $P_{50 \mathrm{H}}$ estimates obtained from the flow-centrifuge method covered a wide range of 272 embolism resistance from -1.85 MPa to -6.02 MPa for Platanus $\times$ acerifolia and Crataegus persimilis, respectively. Parameters estimated with the pneumatic method largely fell into the

274 same range (cf. Table S1). In general, there was a good agreement in overall shape between the 275 flow-centrifuge and pneumatic vulnerability curves (VCs) for most of the species studied. However, the estimates in $P_{12 \mathrm{P}}, P_{50 \mathrm{P}}$ and $P_{88 \mathrm{P}}$ for $T$. cordata and $T$. platyphyllos based on the pneumatic method were on average at least $0.5 \mathrm{MPa}$ higher than the corresponding estimates of the flow-centrifuge method when their xylem pressure was measured using a pressure chamber (Table S1). Additional measurements performed to explain this discrepancy showed that embolism resistance was largely within a comparable range when xylem pressure was determined by stem psychrometers (with the exception of $P_{88 \mathrm{P}}$ for $T$. cordata; Table S1; Fig.

S4). As there were reasons to assume that the differences observed were caused by inaccurate measurement intervals are based only on the observations with xylem pressure measurements based on stem psychrometers.

\section{Overall agreement between methods}

The parameters of the vulnerability curves estimated with the two methods were generally highly correlated, with Pearson correlations above 0.54 for all parameters and over 0.74 for $P_{12}$,

$290 \quad P_{50}$ and $P_{88}$ for all AD times considered in Table S2 and all 12 tree species (Table S2). In 291 particular, this was true for the $P_{50}$ estimates, where correlations exceeded 0.95 in all cases.

292 Moreover, the $P_{50}$ estimates of the two methods were very close to the $1: 1$ line (cf. Fig. $2 \mathrm{~b}$, 293 Table S2). The Pneumatron-based estimates of the slope of the vulnerability curve, however, 294 on average showed a negative systematic deviation that ranged from $-25.5 \%$ (retransformed 
from log scale, $15 \mathrm{sec}$ AD time) to $-28.1 \%$ (115 sec AD time; cf. Fig. 1, 2d; Table S2). The deviation was notably larger in samples with lower slopes, and was not observed for the samples measured with stem psychrometers (Fig. 2). Due to the direct relationship between slope and $P_{50}$, the systematically lower slope estimates translated to a higher $P_{12 \mathrm{P}}$ (by up to $0.77 \mathrm{MPa}$ on average at $115 \mathrm{sec}$ AD time) and, in some cases, a lower $P_{88 \mathrm{P}}$ (by up to $-0.26 \mathrm{MPa}$ on average at $15 \mathrm{sec}$ AD time; Fig. 2, Table S2).

\section{Influence of discharge time}

303 The pneumatic estimates of all VC parameters were sensitive to the chosen discharge time

(Table 2, S2, Fig. 3, 4, 5). However, the change in agreement with air discharge time was neither consistent between parameters nor between species (Table S2, Fig. 4, 5). Consequently, the discharge interval associated with the lowest deviation between flow-centrifuge and pneumatic estimates of $P_{50}$ (Fig. 3) and other parameters differed largely between species, with an Tilia) and a decreasing deviation for others (Ostrya, Platanus, Pyrus and Sorbus). After accounting for random variation between species and trees, significant systematic differences

311 between the reference value based on the flow-centrifuge method and the pneumatic method at all analysed AD times remained for all parameters, with the exception of $P_{88}$ (Table 2).

313 The response of the pneumatic estimates of the vulnerability curve parameters to AD time was 314 not consistent between parameters (Fig. 4). Depending on the parameter, the overall agreement 315 with the flow-centrifuge method was either highest at low AD times $\left(P_{12}\right)$, remained relatively 316 stable over a wide range of $\mathrm{AD}$ times $\left(P_{50}, S_{50}\right)$ or increased continuously with increasing $\mathrm{AD}$ time ( $P_{88}$; cf. Fig. 4). In any case, the $\mathrm{L}_{2}$ distance (which describes the overall match of the curves over their entire range instead of focusing on a point estimate) was lowest at relatively low $\mathrm{AD}$ times with a minimum at $16 \mathrm{sec}$ and a relatively broad range of equivalent values from 
curves corresponded to $\mathrm{AD}$ times in this range, which moreover was associated with the lowest systematic differences in $P_{50}$ estimates (Table 2, S2; Fig. 4).

\section{Discussion}

In agreement with previous assessments of the pneumatic method for vulnerability curve (VC) measurements (Pereira et al., 2016, 2020; Zhang et al., 2018; Sergent et al., 2020), we find that the estimated water potential at $50 \%$ of discharged air volume $\left(P_{50 \mathrm{P}}\right)$ coincide well with the water potential at $50 \%$ loss of conductance $\left(P_{50 \mathrm{H}}\right)$ measured with the flow-centrifuge method for the 12 diffuse-porous temperate tree species studied, with low systematic and random deviations and a high overall agreement $(\mathrm{MSD}=+0.117 \mathrm{MPa}, \rho=0.956, \mathrm{RMSD}= \pm 0.538$ $\mathrm{MPa}$, respectively for $15 \mathrm{sec}$ AD time, Table S2). However, we find evidence for a high variance and systematic differences in the estimates of the slope of the VC (Fig. 1), that were on average at least $25.5 \%$ (15 sec air discharge time, cf. Table S2) lower for the pneumatic

334 method, which also resulted in a lower agreement in the estimates of $P_{12 \mathrm{P}}$ and $P_{88 \mathrm{P}}$. Similar conclusions were found based on a pneumatic modelling approach (Yang et al., 2021), and

336 based on experimental evidence by comparing the pneumatic and the optical method (Pereira 337 et al., 2020; Guan et al., 2021). A mechanistic explanation for the difference in $P_{12}$ and $P_{88}$ 338 values is provided by the open-xylem artefact, which suggests that embolism spreading could 339 be enhanced by the proximity to gas under atmospheric pressure in the open-cut conduits (Guan 340 et al., 2021).

341 Moreover, our results demonstrate that the estimates obtained with the pneumatic method are 342 sensitive to the choice of air discharge time (cf. Pereira et al., 2016, 2020), to which they 343 respond in a nonlinear and species-specific manner. For the analyzed set of species, the best 344 overall match between the flow-centrifuge and pneumatic VCs could be achieved for air 345 discharge times of around $15 \mathrm{sec}$ (cf. Fig. 4), which experimentally confirms the ideal AD time 346 identified by a modelling approach (Yang et al., 2021). 
Agreement between flow-centrifuge and pneumatic vulnerability curves

349 The gradual loss of conductance and the increasing amount of gas extracted, which are quantified by the PLC and PAD, are necessarily positively associated as they share a common cause, namely embolism spreading under progressing dehydration. However, PAD quantifies the air volume inside embolised vessels, while PLC measures their contribution to the conductance of the branch. Thus, both arise from vessel properties that scale with different powers of their length and diameter (Pereira et al., 2016). While the volume of a vessel scales with the second power of diameter and is proportional to its length, its flow resistance (i.e. the inverse of its conductance) can be approximated by the sum of the resistance posed by its lumen and the resistance posed by the transition through pit membranes (Sperry et al., 2005; Wheeler 358 et al., 2005). According to the Hagen-Poseuille-equation, the flow resistance of the lumen scales with the inverse of the fourth power of its diameter and is proportional to its length. The flow resistance posed by the transition through pit membranes can be assumed to scale with the 361 inverse of expected vessel length (Sperry et al., 2005). Due to these different scaling 362 relationships, the association between PAD and PLC does not necessarily have to be linear.

363 Observed systematic differences between the parameters of curves obtained with different 364 methods (cf. Table 2) might therefore not be surprising and deserve further testing.

365 It should also be noted that an additional downward bias in the slope might be introduced by 366 treating the unknown true minimum and maximum amount of air discharged $\left(A D_{\min }\right.$ and $A D_{\max }$, 367 cf. Eq. 1) as fixed quantities measured without error. For hydraulic vulnerability curves, 368 problems induced by treating maximum conductivity as fixed can be circumvented by treating 369 the saturated hydraulic conductivity as a model parameter ( $k_{\text {sat }}$ in Eq. 2; Ogle et al., 2009; 370 Duursma \& Choat, 2017). Implementing a similar solution for the pneumatic method is not 371 straightforward due to the common identifiability issues in sigmoidal models where the lower 372 and upper bound are both treated as model parameters. 
373 Given the direct mathematical relation between the model parameters, a bias in slope can be expected to result in a bias in $P_{12}$ and/or $P_{88}$, which may be problematic in process-based vegetation modelling that use these VC parameters to describe drought resistance. Our results indicate that while the pneumatic method produces reliable estimates of the $P_{50}$ for diffuseporous tree species, the curves obtained might not always be interchangeable with curves 378 constructed with the flow-centrifuge method.

\section{Effect of the air discharge interval on measurement accuracy}

381 The observed sensitivity of the pneumatic method to the AD interval provides experimental evidence that is in line with predictions by the Unit Pipe Pneumatic model (Yang et al., 2021). To understand the relationship between the AD interval and the amount of air discharged in that interval, it is necessary to focus on the underlying assumptions about the gas flow between sample and reservoir. One central assumption of the pneumatic method is that the amount of air discharged into the vacuum reservoir over a given time span is a function of the amount of air $N$ inside embolised conduits at different points during the dehydration process (Jansen et al., 2020; Yang et al.,2021). This assumption is necessary to be able to use PAD measurements to infer the degree of embolization. Further, if the PAD calculated over different AD times $t$ is to result in identical vulnerability curves, the change in $\mathrm{AD}$ with time must have the same shape at different dehydration steps and only differ by a multiplicative constant proportional to the amount of air $N$ in the xylem, i.e. $\operatorname{AD}\left(t, N_{1}\right) / N_{1}=\mathrm{AD}\left(t, N_{2}\right) / N_{2}$ must hold. This assumption is

393 likely only approximately met under typical measurement conditions. During the drying 394 process, the xylem undergoes substantial changes that may affect the shape of $\operatorname{AD}(t, N)$, such as an increase in gas conductivity with progressing embolism. Moreover, it is possible that embolised conduits that were not disconnected from to the cut surface at earlier drying steps 397 subsequently become connected to the network of open vessels connecting to the vacuum 398 reservoir (Pereira et al. 2016). In such cases, the amount of air in these spaces would not be 
included in the earlier estimates. For these reasons, the relationship between the AD measured in different desiccation steps after a certain discharge interval and the total amount of air within the xylem at those points in time is likely empirical. This may explain the pronounced species differences in the response to $\mathrm{AD}$ time (Table S2, 4, Fig. 3), and contribute to the previously reported differences in accuracy for species with different types of wood anatomy (e.g. Zhang et al., 2018).

While the effect of $\mathrm{AD}$ time depended on species identity, and was different for different parameters, Fig. 4 indicates that overall mismatch between flow-centrifuge and pneumatic VCs could be minimized by choosing low AD times of ca.16 sec. In our setting, this might be a consequence of small amounts of air-entry into the xylem where the branch is damaged, which - unlike the other discussed factors influencing $\mathrm{AD}$ - will have an effect that accumulates with discharge time. Thus, the net gains in accuracy due to integrating over a larger time interval are overcompensated by the increasing contribution of potential leakage to the total AD.

412 Interestingly, the higher agreement with hydraulic reference values at lower AD times contrasts 413 with the higher accuracy for longer $\mathrm{AD}$ times reported in earlier works using the manual 414 pneumatic method (cf. Fig. S3 in Pereira et al. 2016). Most likely, this difference results from 415 the higher temporal resolution and more accurate $\mathrm{AD}$ time measurement enabled by the automated Pneumatron device (Pereira et al. 2020). When using a Pneumatron, the choice of short AD times therefore is a pragmatic way to improve the accuracy of the pneumatic method.

\section{Species-specific drying behaviour}

420 As noted previously (Zhang et al., 2018; Sergent et al., 2020), the degree of similarity between

421 VCs measured with the pneumatic method and hydraulic reference methods differs between species. In this study, we observed a mismatch for T. cordata and T. platyphyllos when xylem 
424 However, the difference largely disappeared when a stem psychrometer was used to determine xylem pressure (Fig. 1, S4).

426 Possible explanations for the observed differences is the presence of abundant mucilage in the xylem tissues of Tilia species (Franz \& Kram, 1985; Pigott et al., 2012), which has been reported to affect xylem pressures measured with the pressure chamber technique

429 (Zimmermann et al., 2002). Furthermore, it could be speculated that the truncated shape of the 430 pressure-chamber based Pneumatron VCs for the Tilia species (especially T. cordata, cf. Fig.

431 S4), and the fact they never reached water potentials substantially more negative than $-3 \mathrm{MPa}$,

432 indicates that the measurements were terminated before the stems of the specimens were fully dehydrated. This results in underestimated values for $A D_{\max }$, thus shifting the curve towards

434 less negative water potentials. As detailed before, the desiccation was continued until a near constancy in the measured $A D$ values over at least $24 \mathrm{~h}$ was reached. This criterion to finish $A D$ measurements may not be ideal, as the drying process may slow down notably after full stomatal closure, which especially for isohydric species may happen in a relatively well-hydrated state.

Notably, while Tilia species have often been considered to be relatively anisohydric (cf. Leuzinger et al., 2005; Galiano et al., 2017; Kiorapostolou et al., 2018; but see Niinemets et 440 al., 1999), recent work by Leuschner et al. (2019) indicates that at least T. cordata has a fairly stringent, more isohydric stomatal control mechanism. Due to the anticipated hydraulic segmentation between leaf petioles and stem xylem in drought-avoiding and more isohydric species (Hartmann et al., 2021), this may have contributed to the mismatch between flow-

444 centrifuge and pneumatic VCs. It is well documented that certain species rely on early drought445 induced leaf shedding (Wolfe et al., 2016; Hochberg et al., 2017), most likely caused by a 446 pronounced hydraulic segmentation (cf. Pivovaroff et al., 2016; Zhu et al., 2016; Klepsch et al., 2018). As these processes decouple leaf and branch water potentials, measuring leaf water potential with a Scholander pressure chamber may result in extreme water potential readings 
induced by leaf shedding may result in prematurely terminated measurements when measuring

451 branch water potentials with e.g. a stem psychrometer, or when determining the end of the

452 dehydration process based on the state of the leaves. As a cautionary example, the leaves of

water potential values continued to decline for seven days. Similar behaviour was reported by

Wolfe et al. (2016) for the tropical species Genipa americana.

456 Due to these species-specific differences in drying behaviour, the stability of $A D_{\max }$ can have a

457 strong influence on the shape of the vulnerability curves because all pneumatic $P A D$ values are 458 normalized against $A D_{\min }$ and $A D_{\max }$. It may therefore be advantageous to continue the drying 459 process until the constancy of $A D_{\max }$ has been confirmed based on several measurements to 460 avoid bias resulting from underestimating $A D_{\text {max. }}$ An important corollary of the observed 461 problems associated with water potential measurements is that the same kind of bias in water potential may also affect hydraulic VC measurements in other methods that rely on bench dehydration.

466 An important limitation that affects all evaluation studies of VC methods - as well as most other measurement methods in biology - is the lack of true reference values for $\mathrm{VC}$ parameters. While in this study, we used measurements with the flow-centrifuge method as a reference, there are many indications that this method may be affected by measurement artefacts that arise 470 during sample excision (Wheeler et al., 2013) and preparation (Torres-Ruiz et al., 2015) or as 471 a result from vessel lengths exceeding the sample dimensions (Choat et al., 2010; Martin-StPaul et al., 2014; Torres-Ruiz et al., 2014). A mismatch between curves obtained with the pneumatic method and the flow-centrifuge method may thus in part also be attributed to the imperfections

474 of the latter. While there is hardly a way to overcome the limitation of imperfect reference 475 values, we argue that methodological comparisons of VC methods may benefit from adopting 
a more principled approach of quantifying the agreement between different methods in terms of different components of accuracy (cf. Fuchs et al., 2017; Flo et al., 2019). To our knowledge, none of the previously published methodological comparisons (see e.g. Li et al., 2008; Choat et al., 2010; Hacke et al., 2015; Brodribb et al., 2017; López et al., 2019; Venturas et al., 2019; between systematic and random differences in parameter estimates, and none provide metrics that quantify the similarity over the entire curves. While our choice of the $\mathrm{L}_{2}$-distance as a measure of overall agreement between curves is relatively arbitrary and there are many equally appropriate distance metrics, it is most definitely an improvement compared to the common practice of comparing methods by the Pearson correlation between parameter estimates, as the latter only penalizes deviations from a bivariate linear relationship while being insensitive to systematic deviations. We hope that our framework can serve as a starting point for more formal VC method comparisons based on rigorous metrological principles and theory.

\section{Conclusions}

491 Our data indicate a high degree of agreement between the $P_{50 \mathrm{P}}$ estimated with the pneumatic 492 method and the $P_{50 \mathrm{H}}$ estimated with the flow-centrifuge method for the analysed diffuse-porous temperate tree species, especially when using short air discharge times of around $15 \mathrm{sec}$. The relatively low effort required to construct a curve with this method and its high degree of automation when using a Pneumatron device in conjunction with a stem psychrometer allow

496 for a high throughput. The method is therefore attractive in descriptive or predictive contexts 497 where the main purpose is to generate a good proxy for plant drought resistance. However, the 498 observed systematic deviation in slope estimates as well as potential artefacts associated with 499 xylem water potential determination and species-specific drying behaviour deserve further attention. 


\section{Acknowledgements}

503 We thank Klaus Körber and Andreas Lösch from the Bavarian state institute for viticulture and 504 horticulture (Bayerische Landesanstalt für Wein- und Gartenbau, LWG) for granting access to 505 their research facility at Stutel and Xinyi Guan for her support with the automated pneumatic 506 measurements. P.R.L.B. acknowledges Royal Society's Newton International for its Fellowship 507 (NF170370). S.J. acknowledges funding from the German Research Foundation (Deutsche 508 Forschungsgemeinschaft, DFG, project nr. 410768178).

\section{Author contributions}

511 B.S. and R.M.L. designed the study, S.S.P. performed the semi-automated pneumatic 512 measurements, technically supported by P.B. and L.P., L.P. the automated pneumatic 513 measurements and E.I. the hydraulic measurements. S.S.P. and R.M.L. analysed the data. S.S.P, 514 R.M.L. and B.S. wrote the first manuscript, which was intensively discussed and revised by all 515 authors. 


\section{References}

Adams HD, Zeppel MJB, Anderegg WRL, Hartmann H, Landhäusser SM, Tissue DT, Huxman TE, Hudson PJ, Franz TE, Allen CD, et al. 2017. A multi-species synthesis of physiological mechanisms in drought-induced tree mortality. Nature Ecology \& Evolution 1: 1285-1291.

Allen CD, Breshears DD, McDowell NG. 2015. On underestimation of global vulnerability to tree mortality and forest die-off from hotter drought in the Anthropocene. Ecosphere 6: 1-55.

Allen CD, Macalady AK, Chenchouni H, Bachelet D, McDowell N, Vennetier M, Kitzberger T, Rigling A, Breshears DD, Hogg EH (Ted), et al. 2010. A global overview of drought and heatinduced tree mortality reveals emerging climate change risks for forests. Forest Ecology and Management 259: 660-684.

Anderegg WRL, Klein T, Bartlett M, Sack L, Pellegrini AFA, Choat B, Jansen S. 2016. Metaanalysis reveals that hydraulic traits explain cross-species patterns of drought-induced tree mortality across the globe. Proceedings of the National Academy of Sciences 113: 5024-5029.

Bates D, Mächler M, Bolker B, Walker S. 2015. Fitting linear mixed-effects models using lme4. Journal of Statistical Software 67: 1-48.

Bittencourt PRL, Pereira L, Oliveira RS. 2018. Pneumatic Method to Measure Plant Xylem Embolism. Bio-Protocol 8.

Blackman CJ, Gleason SM, Chang Y, Cook AM, Laws C, Westoby M. 2014. Leaf hydraulic vulnerability to drought is linked to site water availability across a broad range of species and climates. Annals of Botany 114: 435-440.

Brando PM, Paolucci L, Ummenhofer CC, Ordway EM, Hartmann H, Cattau ME, Rattis L, Medjibe V, Coe MT, Balch J. 2019. Droughts, Wildfires, and Forest Carbon Cycling: A Pantropical Synthesis. Annual Review of Earth and Planetary Sciences 47: 555-581.

Brodersen CR, McElrone AJ, Choat B, Matthews MA, Shackel KA. 2010. The Dynamics of Embolism Repair in Xylem: In Vivo Visualizations Using High-Resolution Computed Tomography. Plant Physiology 154: 1088-1095.

Brodribb TJ, Cochard H. 2009. Hydraulic Failure Defines the Recovery and Point of Death in WaterStressed Conifers. Plant Physiology 149: 575-584.

Brodribb TJ, Skelton RP, McAdam SA, Bienaimé D, Lucani CJ, Marmottant P. 2016. Visual quantification of embolism reveals leaf vulnerability to hydraulic failure. New Phytologist 209: $1403-1409$.

Brodribb TJ, Carriqui M, Delzon S, Lucani C. 2017. Optical Measurement of Stem Xylem Vulnerability. Plant Physiology 174: 2054-2061. 
Brodribb TJ, Powers J, Cochard H, Choat B. 2020. Hanging by a thread? Forests and drought. Science 368: 261-266.Chen Y, Maenpuen P, Zhang Y, Barai K, Katabuchi M, Gao H, Kaewkamol S, Tao L, Zhang J. 2020. Quantifying vulnerability to embolism in tropical trees and lianas using five methods: can discrepancies be explained by xylem structural traits? New Phytologist 229: 805-819.

Chen Y, Maenpuen P, Zhang Y, Barai K, Katabuchi M, Gao H, Kaewkamol S, Tao L, Zhang J. 2021. Quantifying vulnerability to embolism in tropical trees and lianas using five methods: can discrepancies be explained by xylem structural traits? New Phytologist 229: 805-819.

Choat B, Drayton WM, Brodersen C, Matthews MA, Shackel KA, Wada H, Mcelrone AJ. 2010. Measurement of vulnerability to water stress-induced cavitation in grapevine: a comparison of four techniques applied to a long-vesseled species: Comparison of vulnerability curve technique in grapevine. Plant, Cell \& Environment 491: 752-755.

Choat B, Jansen S, Brodribb TJ, Cochard H, Delzon S, Bhaskar R, Bucci SJ, Feild TS, Gleason SM, Hacke UG et al. 2012. Global convergence in the vulnerability of forests to drought. Nature 491: 752-755.

Choat B, Brodribb TJ, Brodersen CR, Duursma RA, López R, Medlyn BE. 2018. Triggers of tree mortality under drought. Nature 558: 531-539.

Christoffersen BO, Gloor M, Fauset S, Fyllas NM, Galbraith DR, Baker R, Kruijt B, Rowland L, Fisher RA, Binks OJ et al. 2016. Linking hydraulic traits to tropical forest function in a size-

Cochard H, Cruiziat P, Tyree MT. 1992. Use of Positive Pressures to Establish Vulnerability Curves. Plant Physiology 100: 205-209.

Cochard H, Damour G, Bodet C, Tharwat I, Poirier M, Améglio T. 2005. Evaluation of a new centrifuge technique for rapid generation of xylem vulnerability curves. Physiologia Plantarum 124: $410-418$.

Cochard H, Badel E, Herbette S, Delzon S, Choat B, Jansen S. 2013. Methods for measuring plant vulnerability to cavitation: a critical review. Journal of Experimental Botany 64: 4779-4791.

Correia DLP, Bouchard M, Filotas É, Raulier F. 2019. Disentangling the effect of drought on stand mortality and productivity in northern temperate and boreal forests. Journal of Applied Ecology 56: $758-768$. 
Davi H, Cailleret M. 2017. Assessing drought-driven mortality trees with physiological process-based models. Agricultural and Forest Meteorology 232: 279-290.

Delzon S, Cochard H. 2014. Recent advances in tree hydraulics highlight the ecological significance of the hydraulic safety margin. New Phytologist 203: 355-358.

Duursma RA, Choat B. 2017. fitple : an R package to fit hydraulic vulnerability curves. Journal of Plant Hydraulics 4: e002.

Eller CB, Rowland L, Mencuccini M, Rosas T, Williams K, Harper A, Medlyn BE, Wagner Y, Klein T, Teodoro GS, et al. 2020. Stomatal optimization based on xylem hydraulics (SOX) improves land surface model simulation of vegetation responses to climate. New Phytologist 226: $1622-1637$.

Field CB, Barros V, Stocker TF, Dahe Q (Eds.). 2012. Managing the Risks of Extreme Events and Disasters to Advance Climate Change Adaptation: Special Report of the Intergovernmental Panel on Climate Change. Cambridge: Cambridge University Press.

Flo V, Martinez-Vilalta J, Steppe K, Schuldt B, Poyatos R. 2019. A synthesis of bias and uncertainty in sap flow methods. Agricultural and Forest Meteorology 271: 362-374.

Franz G, Kram G. 1985. Structural investigations on the watersoluble polysaccharides of lime tree flowers. Die Pharmazie 41: 501.

Fuchs S, Leuschner C, Link R, Coners H, Schuldt B. 2017. Calibration and comparison of thermal dissipation, heat ratio and heat field deformation sap flow probes for diffuse-porous trees. Agricultural and Forest Meteorology 244-245: 151-161.

Guan X., Pereira L., McAdam S.A.M., Cao K., Jansen S. 2021. No gas source, no problem: proximity to pre-existing embolism and segmentation affect embolism spreading in angiosperm xylem by gas diffusion. Plant, Cell \& Environment. doi: 10.1111/pce.14016.

Hacke UG, Venturas MD, MacKinnon ED, Jacobsen AL, Sperry JS, Pratt RB. 2015. The standard centrifuge method accurately measures vulnerability curves of long-vesselled olive stems. New Phytologist 205: 116-127.

Hartmann H, Link RM, Schuldt B. 2021. A whole-plant perspective of isohydry: stem-level support for leaf-level plant water regulation. Tree Physiology, accepted. 
Jansen S, Schuldt B, Choat B. 2015. Current controversies and challenges in applying plant hydraulic techniques. New Phytologist 205: 961-964.

Jansen S, Guan X, Kaack L, Trabi C, Miranda M, Ribeiro R, Pereira L. 2020. The Pneumatron estimates xylem embolism resistance in angiosperms based on gas diffusion kinetics: a minireview. Acta Horticulturae 1300: 193-200.

Kiorapostolou N, Galiano-Pérez L, von Arx G, Gessler A, Petit G. 2018. Structural and anatomical responses of Pinus sylvestris and Tilia platyphyllos seedlings exposed to water shortage. Trees 32: $1211-1218$.

Klepsch M, Zhang Y, Kotowska MM, Lamarque LJ, Nolf M, Schuldt B, Torres-Ruiz JM, Qin DW, Choat B, Delzon S, et al. 2018. Is xylem of angiosperm leaves less resistant to embolism than branches? Insights from microCT, hydraulics, and anatomy. Journal of Experimental Botany 69: $5611-5623$.

Kuznetsova A, Brockhoff PB, Christensen RHB. 2017. 1merTest Package: Tests in Linear Mixed Effects Models. Journal of Statistical Software 82: 1-26.

Leuschner C, Wedde P, Lübbe T. 2019. The relation between pressure-volume curve traits and stomatal regulation of water potential in five temperate broadleaf tree species. Annals of Forest Science 76: 60 .

Leuzinger S, Zotz G, Asshoff R, Korner C. 2005. Responses of deciduous forest trees to severe drought in Central Europe. Tree Physiology 25: 641-650.

Li Y, Sperry JS, Taneda H, Bush SE, Hacke UG. 2008. Evaluation of centrifugal methods for

López R, Nolf M, Duursma RA, Badel E, Flavel RJ, Cochard H, Choat B. 2019. Mitigating the open vessel artefact in centrifuge-based measurement of embolism resistance ( $\mathrm{R}$ Tognetti, Ed.). Tree Physiology 39: 143-155.

Martin-StPaul NK, Longepierre D, Huc R, Delzon S, Burlett R, Joffre R, Rambal S, Cochard H. 2014. How reliable are methods to assess xylem vulnerability to cavitation? The issue of 'open vessel' artifact in oaks. Tree Physiology 34: 894-905.

Martin-StPaul N, Delzon S, Cochard H. 2017. Plant resistance to drought depends on timely stomatal closure. Ecology Letters 20: 1437-1447. multimodel-experiment framework. New Phytologist 200: 304-321. 
McDowell NG, Ryan MG, Zeppel MJB, Tissue DT. 2013b. Feature: Improving our knowledge of drought-induced forest mortality through experiments, observations, and modeling. New Phytologist 200: 289-293.

Meinzer FC, Johnson DM, Lachenbruch B, McCulloh KA, Woodruff DR. 2009. Xylem hydraulic safety margins in woody plants: coordination of stomatal control of xylem tension with hydraulic capacitance. Functional Ecology 23: 922-930.

Niinemets Ü, Sõber A, Kull O, Hartung W, Tenhunen JD. 1999. Apparent Controls on Leaf Conductance by Soil Water Availability and via Light-Acclimation of Foliage Structural and Physiological Properties in a Mixed Deciduous, Temperate Forest. International Journal of Plant Sciences 160: 707-721.

Nolf M, López R, Peters J, Flavel R, Koloadin L, Young I, Choat B. 2017. Visualization of xylem embolism by X-ray microtomography: A direct test against hydraulic measurements. New Phytologist 214: 890-898.

Ogle K, Barber JJ, Willson C, Thompson B. 2009. Hierarchical statistical modeling of xylem vulnerability to cavitation. New Phytologist 182: 541-554.

Oliveira RS, Costa FRC, Baalen E van, Jonge A de, Bittencourt PR, Almanza Y, Barros F de V, Cordoba EC, Fagundes MV, Garcia S et al. 2019. Embolism resistance drives the distribution of Amazonian rainforest tree species along hydro-topographic gradients. New Phytologist 221: $1457-1465$.

Pammenter NW, Vander Willigen C. 1998. A mathematical and statistical analysis of the curves illustrating vulnerability of xylem to cavitation. Tree Physiology 18: 589-593.

Pereira L, Bittencourt PRL, Oliveira RS, Junior MBM, Barros FV, Ribeiro RV, Mazzafera P. 2016. Plant pneumatics: stem air flow is related to embolism - new perspectives on methods in plant hydraulics. New Phytologist 211: 357-370.

Pereira L, Bittencourt PRL, Pacheco VS, Miranda MT, Zhang Y, Oliveira RS, Groenendijk P, Machado EC, Tyree MT, Jansen S et al. 2020. The Pneumatron: An automated pneumatic apparatus for estimating xylem vulnerability to embolism at high temporal resolution. Plant, Cell \& Environment 43: 131-142.

Pigott D. 2012. Lime-trees and Basswoods: A Biological Monograph of the Genus Tilia. Cambridge 'microbubble effect' using the Cavitron technique to measure xylem water extraction curves. $A o B$ Plants 8. 

hydraulically vulnerable tree species. Global Change Biology 26: 3122-3133.

Pratt RB, Castro V, Fickle JC, Jacobsen AL. 2020. Embolism resistance of different aged stems of a California oak species (Quercus douglasii): optical and microCT methods differ from the benchtop-dehydration standard (M Ball, Ed.). Tree Physiology 40: 5-18.

Pya N. 2020. scam: Shape Constrained Additive Models. $R$ package version 1.2-8. URL: https://CRAN.R-project.org/package=scam

R Core Team. 2020. R: A language and environment for statistical computing. Vienna, Austria. approaches to meta-analytic inference. In: Handbook of meta-analysis in ecology and evolution. Princeton and Oxford: Princeton University Press, 108-124.

Rosner S, Heinze B, Savi T, Dalla-Salda G. 2019. Prediction of hydraulic conductivity loss from relative water loss: new insights into water storage of tree stems and branches. Physiologia ME, Guillemot J, Gyenge $\mathbf{J}$ et al. 2020. A comparison of five methods to assess embolism resistance in trees. Forest Ecology and Management 468: 118175.

Sperry JS, Tyree MT. 1988. Mechanism of Water Stress-Induced Xylem Embolism. Plant Physiology 88: $581-587$.

Sperry JS, Hacke UG, Wheeler JK. 2005. Comparative analysis of end wall resistivity in xylem conduits. Plant, Cell \& Environment 28: 456-465.

Torres-Ruiz JM, Cochard H, Mayr S, Beikircher B, Diaz-Espejo A, Rodriguez-Dominguez CM, Badel E, Fernández JE. 2014. Vulnerability to cavitation in Olea europaea current-year shoots: the Induction of Embolism upon Xylem Cutting under Tension. Plant Physiology 167: 40-43. 
Trueba S, Pouteau R, Lens F, Feild TS, Isnard S, Olson ME, Delzon S. 2017. Vulnerability to xylem embolism as a major correlate of the environmental distribution of rain forest species on a tropical island. Plant, Cell \& Environment 40: 277-289.

Urli M, Porte AJ, Cochard H, Guengant Y, Burlett R, Delzon S. 2013. Xylem embolism threshold for catastrophic hydraulic failure in angiosperm trees. Tree Physiology 33: 672-683.

Venturas MD, Pratt RB, Jacobsen AL, Castro V, Fickle JC, Hacke UG. 2019. Direct comparison of four methods to construct xylem vulnerability curves: Differences among techniques are linked to vessel network characteristics. Plant, Cell \& Environment 42: 2422-2436.

Wheeler JK, Huggett BA, Tofte AN, Rockwell FE, Holbrook NM. 2013. Cutting xylem under tension or supersaturated with gas can generate PLC and the appearance of rapid recovery from embolism: Sampling induced embolism. Plant, Cell \& Environment 36: 1938-1949.

Wheeler JK, Sperry JS, Hacke UG, Hoang N. 2005. Inter-vessel pitting and cavitation in woody Rosaceae and other vesselled plants: a basis for a safety versus efficiency trade-off in xylem transport. Plant, Cell \& Environment 28: 800-812.

Wickham H, Averick M, Bryan J, Chang W, McGowan LD, François R, Grolemund G, Hayes A, Henry L, Hester J, et al. 2019. Welcome to the Tidyverse. Journal of Open Source Software 4: 1686.

Wolfe BT, Sperry JS, Kursar TA. 2016. Does leaf shedding protect stems from cavitation during seasonal droughts? A test of the hydraulic fuse hypothesis. New Phytologist 212: 1007-1018.

Wu M, Zhang Y, Oya T, Marcati CR, Pereira L, Jansen S. 2020. Root xylem in three woody angiosperm species is not more vulnerable to embolism than stem xylem. Plant and Soil 450: 479-495.

Xu X, Medvigy D, Powers JS, Becknell JM, Guan K. 2016. Diversity in plant hydraulic traits explains seasonal and inter-annual variations of vegetation dynamics in seasonally dry tropical forests. New Phytologist 212: 80-95.

Yang D., Pereira P., Peng G., Ribeiro R.V., Kaack L., Jansen S., Tyree M.T. Submitted.

A Unit Pipe Pneumatic model to simulate gas kinetics during measurements of embolism in excised angiosperm xylem. bioRxiv, https://doi.org/10.1101/2021.02.09.430450. Burlett R, Cao K-F, et al. 2018. Testing the plant pneumatic method to estimate xylem embolism resistance in stems of temperate trees. Tree Physiology 38: 1016-1025.

Zhao H, Jiang Z, Ma J, Cai J. 2020. What causes the differences in cavitation resistance of two shrubs? Wood anatomical explanations and reliability testing of vulnerability curves. Physiologia Plantarum 169: 156-168. 
749 Zhu S-D, Liu H, Xu Q-Y, Cao K-F, Ye Q. 2016. Are leaves more vulnerable to cavitation than branches? Functional Ecology 30: 1740-1744.

751 Zimmermann U, Wagner H-J, Heidecker M, Mimietz S, Schneider H, Szimtenings M, Haase A, Mitlöhner R, Kruck W, Hoffmann R, et al. 2002. Implications of mucilage on pressure bomb measurements and water lifting in trees rooting in high-salinity water. Trees 16: 100-111. 


\section{Tables}

Table 1: List of the 12 diffuse-porous tree species used in the present study, average midday leaf water potential ( $\left.\Psi_{\text {midday}}\right)$ measured in August 2020 and the average diameter at breast height $(\mathrm{DBH})$ of the selected trees per species (mean $\pm \mathrm{SE}) ; n_{\mathrm{P}}$ and $n_{\mathrm{H}}$ indicate the number of xylem vulnerability curves measured for the pneumatic and the flow-centrifuge method, respectively (values in brackets indicate when branch samples were collected from a single tree). Asterisks (*) indicate xylem pressures measured with stem psychrometers; hashes (\#) indicate individuals from the same species measured with the pressure bomb.

\begin{tabular}{llrrrr}
\hline Species & Family & $\boldsymbol{n}_{\mathbf{P}}$ & $\boldsymbol{n}_{\mathbf{H}}$ & $\boldsymbol{\Psi}_{\text {midday }}(\mathbf{M P a})$ & $\mathbf{D B H}(\mathbf{c m})$ \\
\hline Betula pendula & Betulaceae & 3 & 3 & $-1.60 \pm 0.04$ & $10.93 \pm 0.64$ \\
Betula utilis & Betulaceae & 3 & 3 & $-1.54 \pm 0.06$ & $08.88 \pm 0.42$ \\
Carpinus betulus & Betulaceae & 3 & 3 & $-2.47 \pm 0.06$ & $10.75 \pm 0.44$ \\
Crataegus persimilis & Rosaceae & 3 & 3 & $-3.42 \pm 0.18$ & $07.55 \pm 0.16$ \\
Ostrya carpinifolia & Betulaceae & 3 & 3 & $-2.97 \pm 0.11$ & $09.18 \pm 0.11$ \\
Platanus x acerifolia & Platanaceae & 3 & 3 & $-1.74 \pm 0.03$ & $10.00 \pm 0.24$ \\
Platanus orientalis & Platanaceae & 3 & 3 & $-1.51 \pm 0.04$ & $12.07 \pm 0.35$ \\
Pyrus calleryana & Rosaceae & 2 & 3 & $-3.52 \pm 0.30$ & $11.88 \pm 0.32$ \\
Sorbus latifolia & Rosaceae & 3 & 3 & $-3.64 \pm 0.19$ & $09.30 \pm 0.39$ \\
Tilia cordata* & Malvaceae & $5(1)$ & $5(1)$ & $\mathrm{NA}$ & $28.00 \pm 0.00$ \\
Tilia cordata\# & Malvaceae & 3 & 3 & $-1.90 \pm 0.04$ & $11.40 \pm 0.46$ \\
Tilia japonica & Malvaceae & $3(1)$ & $4(1)$ & $\mathrm{NA}$ & $30.40 \pm 0.00$ \\
Tilia platyphyllos* & Malvaceae & $4(1)$ & $7(1)$ & $\mathrm{NA}$ & $70.00 \pm 0.21$ \\
Tilia platyphyllos\# & Malvaceae & 3 & 3 & $-1.80 \pm 0.08$ & $12.38 \pm 0.21$ \\
\hline
\end{tabular}


Table 2: Parameter estimates of the linear mixed effect models for the xylem water potential at $12 \%, 50 \%$ and $88 \%$ loss of conductivity $\left(P_{12}, P_{50}\right.$ and $P_{88}$, respectively) and the natural logtransformed slope at $50 \%$ loss of conductivity $\left(S_{50}\right)$. Given are estimates for the intercept (average for flow-centrifuge based reference value) as well as the differences from the reference for different $\mathrm{AD}$ times, with the corresponding standard errors, $t$-statistics, approximate degrees of freedom based on the Satterthwaite approximation and corresponding $P$-values.

\begin{tabular}{|c|c|c|c|c|c|c|}
\hline Parameter & Treatment & Estimate & Std.error & $t$-statistic & edf & $P$-value \\
\hline \multirow[t]{6}{*}{$P_{12}$} & (Intercept) & -2.814 & 0.32 & -8.79 & 12.085 & $<0.001$ \\
\hline & $\Delta 15 \mathrm{~s}$ & 0.444 & 0.086 & 5.144 & 198.53 & $<0.001$ \\
\hline & $\Delta 30 \mathrm{~s}$ & 0.532 & 0.086 & 6.163 & 198.53 & $<0.001$ \\
\hline & $\Delta 60 \mathrm{~s}$ & 0.631 & 0.086 & 7.311 & 198.53 & $<0.001$ \\
\hline & $\Delta 90 \mathrm{~s}$ & 0.702 & 0.086 & 8.13 & 198.53 & $<0.001$ \\
\hline & $\Delta 115 \mathrm{~s}$ & 0.758 & 0.086 & 8.781 & 198.53 & $<0.001$ \\
\hline \multirow[t]{6}{*}{$P_{50}$} & (Intercept) & -3.652 & 0.495 & -7.383 & 11.154 & $<0.001$ \\
\hline & $\Delta 15 \mathrm{~s}$ & 0.114 & 0.056 & 2.037 & 202.67 & 0.043 \\
\hline & $\Delta 30 \mathrm{~s}$ & 0.184 & 0.056 & 3.284 & 202.67 & 0.001 \\
\hline & $\Delta 60 \mathrm{~s}$ & 0.259 & 0.056 & 4.632 & 202.67 & $<0.001$ \\
\hline & $\Delta 90 \mathrm{~s}$ & 0.305 & 0.056 & 5.453 & 202.67 & $<0.001$ \\
\hline & $\Delta 115 \mathrm{~s}$ & 0.332 & 0.056 & 5.936 & 202.67 & $<0.001$ \\
\hline \multirow[t]{6}{*}{$P_{88}$} & (Intercept) & -4.512 & 0.699 & -6.451 & 11.263 & $<0.001$ \\
\hline & $\Delta 15 \mathrm{~s}$ & -0.213 & 0.094 & -2.265 & 200.67 & 0.025 \\
\hline & $\Delta 30 \mathrm{~s}$ & -0.162 & 0.094 & -1.718 & 200.67 & 0.087 \\
\hline & $\Delta 60 \mathrm{~s}$ & -0.11 & 0.094 & -1.169 & 200.67 & 0.244 \\
\hline & $\Delta 90 \mathrm{~s}$ & -0.089 & 0.094 & -0.945 & 200.67 & 0.346 \\
\hline & $\Delta 115 \mathrm{~s}$ & -0.091 & 0.094 & -0.968 & 200.67 & 0.334 \\
\hline \multirow[t]{6}{*}{$S_{50}$} & (Intercept) & 4.258 & 0.2 & 21.30 & 12.452 & $<0.001$ \\
\hline & $\Delta 15 \mathrm{~s}$ & -0.253 & 0.081 & -3.124 & 204.53 & 0.002 \\
\hline & $\Delta 30 \mathrm{~s}$ & -0.266 & 0.081 & -3.284 & 204.53 & 0.001 \\
\hline & $\Delta 60 \mathrm{~s}$ & -0.287 & 0.081 & -3.536 & 204.53 & $<0.001$ \\
\hline & $\Delta 90 \mathrm{~s}$ & -0.303 & 0.081 & -3.742 & 204.53 & $<0.001$ \\
\hline & $\Delta 115 \mathrm{~s}$ & -0.326 & 0.081 & -4.022 & 204.53 & $<0.001$ \\
\hline
\end{tabular}




\section{Figure captions}

Figure 1: Xylem vulnerability curves obtained with the pneumatic method after a measurement duration of $15 \mathrm{sec}$ (green) and the flow-centrifuge method (blue) for 12 diffuse-porous tree species. Circles: observed values (for the centrifuge data, rescaled from conductance to PLC using the estimated $k_{\text {sat }}$ ); solid lines: predicted PLC/PAD; dashed lines: estimated $P_{50}$. Asterisks (*) at the end of species names indicate xylem pressure measurements with stem psychrometers.

Figure 2: Relationship between estimates from the flow-centrifuge method (x-axis) and the pneumatic method with $15 \mathrm{sec}$ air discharge interval (y-axis). a) $P_{12}$, b) $P_{50}$, c) $P_{88}($ xylem water potentials at $12 \%, 50 \%$ and $88 \%$, respectively) and d) slope at $50 \%$ loss of conductivity (displayed on a log scale). Colours - species identity (empty circles indicate pressure chamberbased Tilia measurements); solid black line - standardized major axis (SMA) regression fit through all points $\pm 95 \%$ bootstrap confidence interval; grey dashed line: 1:1 line.

Figure 3: Comparison of $P_{50}$ values between the flow-centrifuge and different air discharge intervals for the pneumatic method (compared on the same branch). C indicates the $P_{50}$ values from the flow-centrifuge method, 15, 30, 60, 90, and 115 indicate $\mathrm{AD}$ measurement intervals (in seconds) evaluated from the pneumatic method. Shown are the raw estimates overlaid with their mean \pm SE. Asterisks $\left(^{*}\right)$ at the end of species name indicate xylem pressure was determined using stem psychrometer.

Figure 4: Statistics describing the agreement between the estimated vulnerability curve parameters from the pneumatic method and the flow-centrifuge method vs. the duration of air 
discharge measurement (estimates $\pm 95 \%$ bootstrap confidence intervals based on 1,000 bootstrap draws). The metrics shown are the Pearson correlation (Pearson $\rho$ ) as a measure of random deviation between the two methods (values close to one indicate a perfect linear relationship), mean signed deviation (MSD) as a measure of systematic deviations (values close to zero indicate a low bias), and root mean square deviation (RMSD) as a measure of overall agreement (low values indicate a high agreement between methods).

Figure 5: Average $\mathrm{L}_{2}$ distance between the pneumatic and flow-centrifuge vulnerability curves vs. air discharge time as a measure of overall accuracy (raw averages and \pm 5 s running average). Vertical lines indicate the minimum of the running average at $16 \mathrm{sec}$; the shaded area indicates the range with a running average differing from the minimum by less than $1 \%(10.5$ $-44.5 \mathrm{sec})$. 
bioRxiv preprint doi: https://doi.org/10.1101/2021.02.15.431295; this version posted February 16, 2021. The copyright holder for this preprint (which was not certified by peer review) is the author/funder. All rights reserved. No reuse allowed without permission.
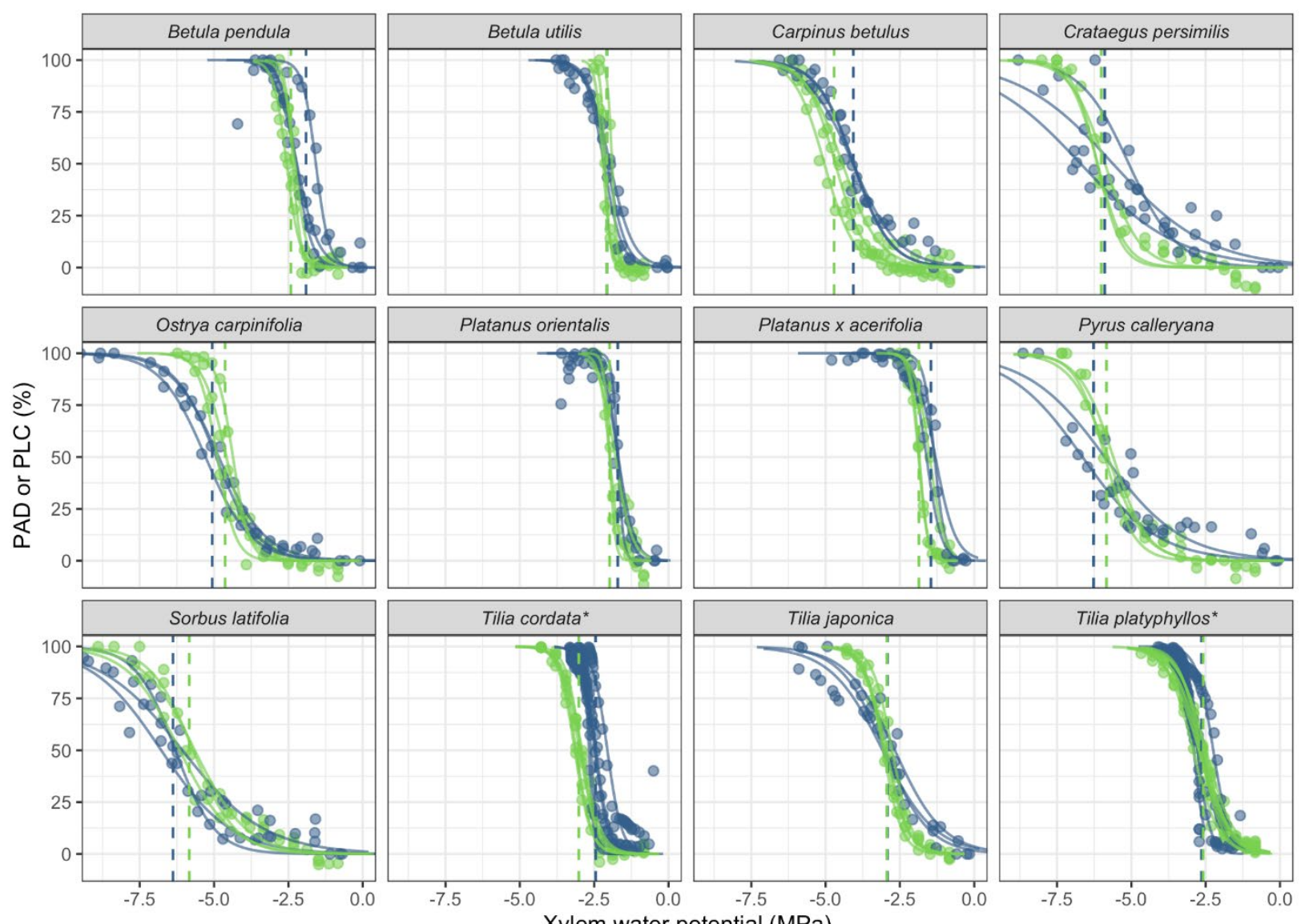

is Pneumatic method (15 s AD interval) $\frac{b}{\text { I }}$ Flow-centrifuge method

\section{Figure 1}



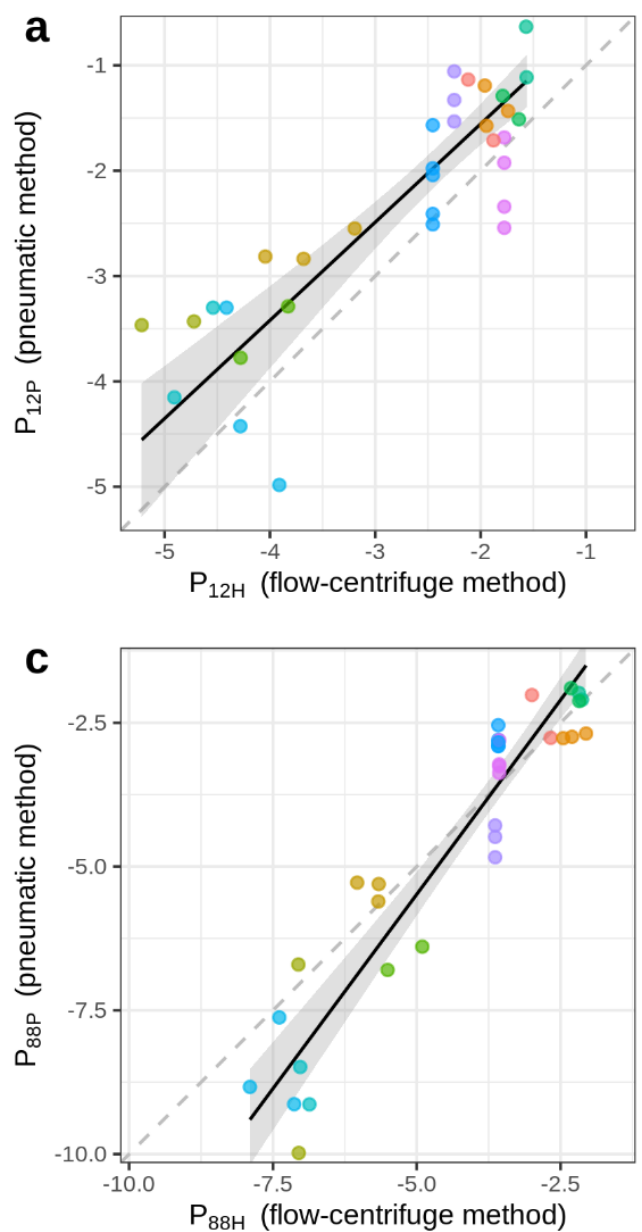
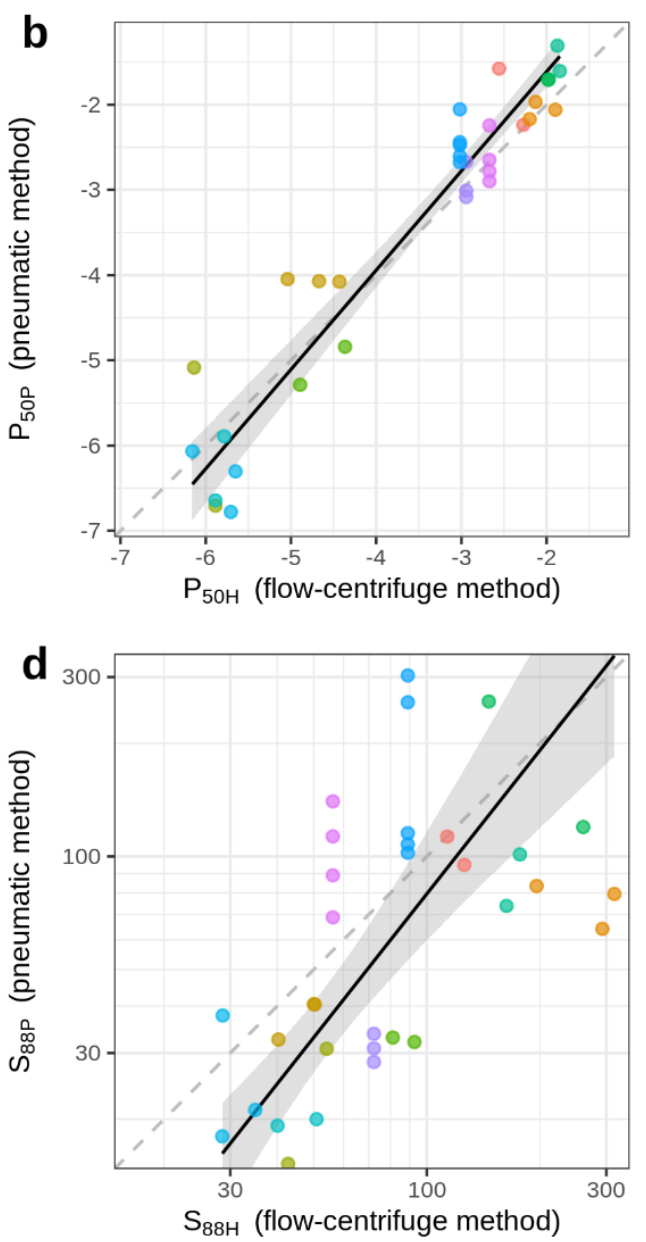

Betula pendula

Betula utilis

- Carpinus betulus

- Crataegus persimilis

- Ostrya carpinifolia

- Platanus orientalis

- Platanus x acerifolia

- Pyrus calleryana

Sorbus latifolia

- Tilia cordata

- Tilia japonica

- Tilia platyphyllos

Figure 2 


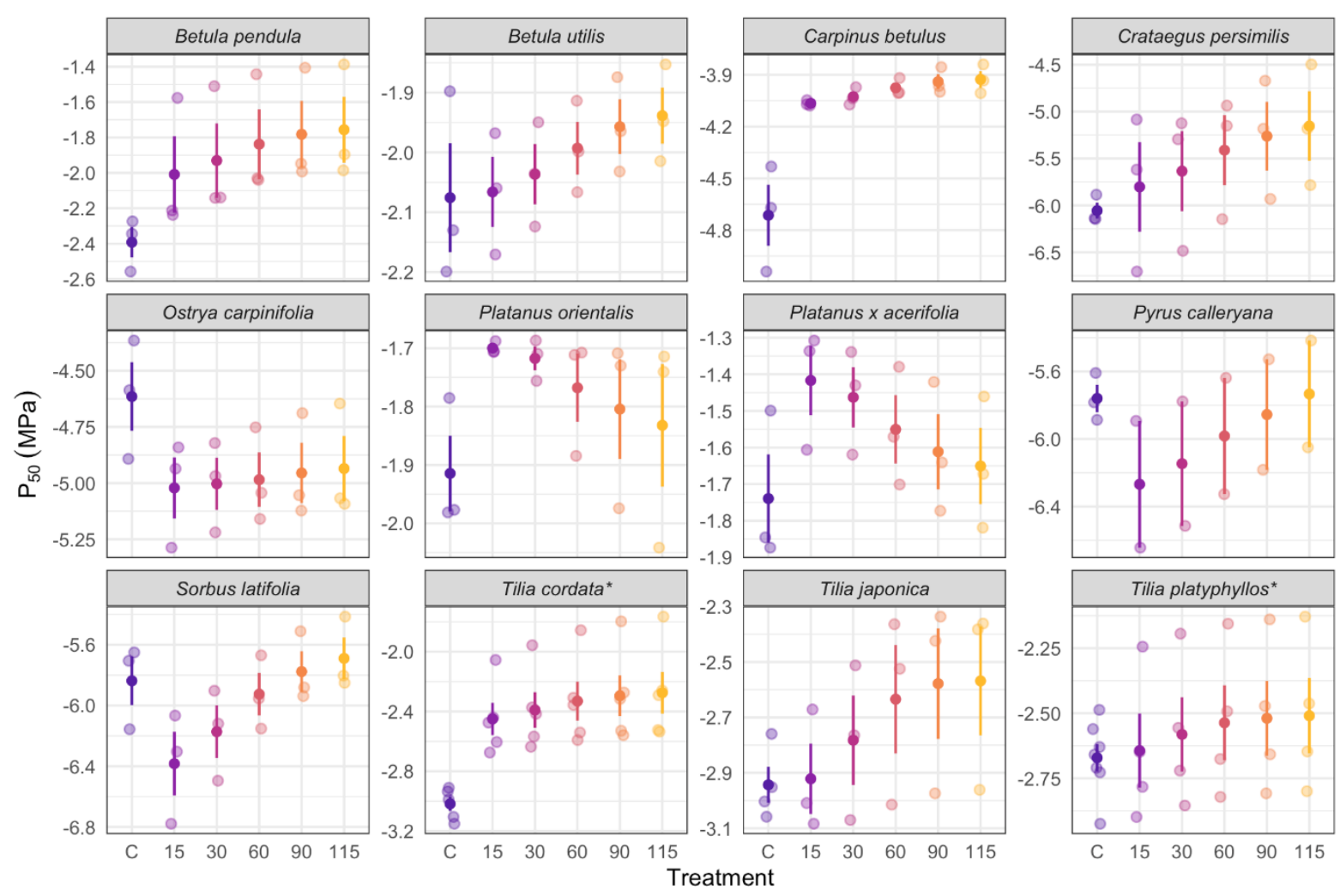

Figure 3 

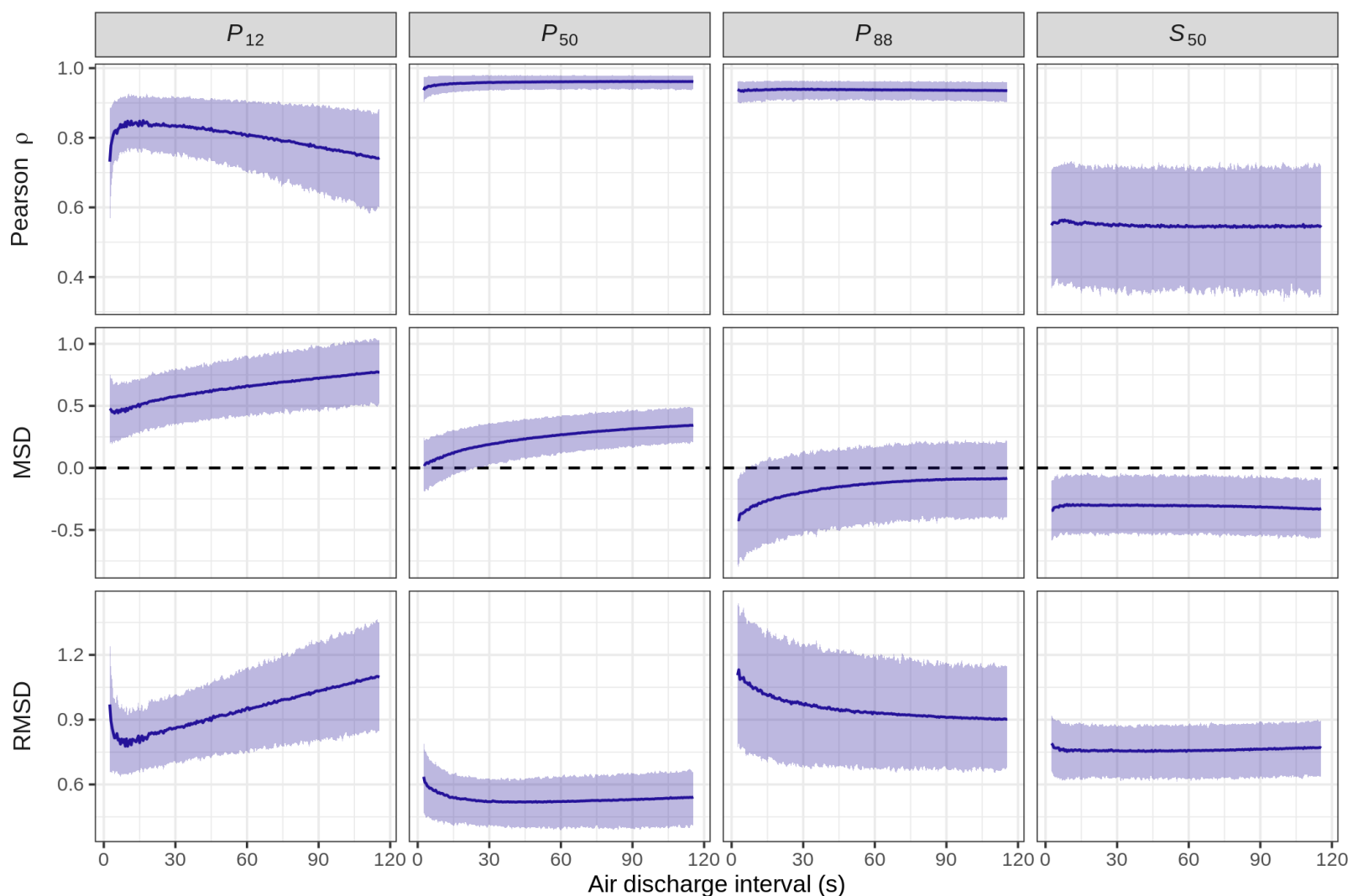

Figure 4 
bioRxiv preprint doi: https://doi.org/10.1101/2021.02.15.431295; this version posted February 16, 2021. The copyright holder for this

preprint (which was not certified by peer review) is the author/funder. All rights reserved. No reuse allowed without permission.

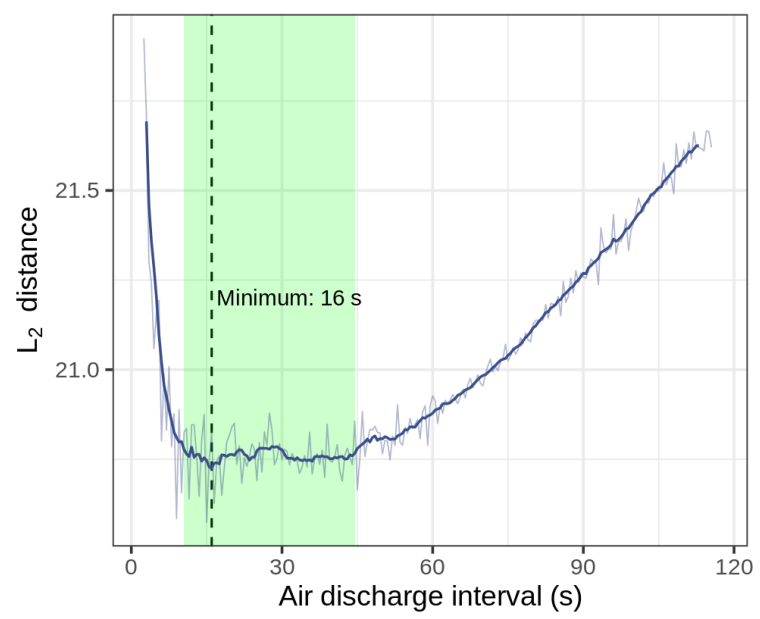

Figure 5 